\title{
Tarsal navicular stress fractures
}

\author{
Rachel J. Shakked $^{1}$ • Emily E. Walters ${ }^{2}$ - Martin J. O'Malley ${ }^{3}$
}

Published online: 21 January 2017

(C) Springer Science+Business Media New York 2017

\begin{abstract}
Purpose of review Navicular stress fractures are common in athletes and management is debated. This article will review the evaluation and management of navicular stress fractures. Recent findings Various operative and non-operative adjunctive treatment modalities are reviewed including the relevance of vitamin D levels, use of shock wave therapy and bone marrow aspirate concentrate (BMAC), and administration of teriparatide. Surgical treatment may be associated with earlier return to sports.

Summary The author's preferred treatment algorithm with corresponding images is presented which allows for safe and rapid return to activities in the athletic patient. Future research is needed in evaluating the preventative effects of vitamin D and use of other adjunctive treatments to increase the healing rates of this fracture.
\end{abstract}

Keywords Navicular $\cdot$ Stress fracture $\cdot$ Vitamin D

\section{Introduction/epidemiology}

While rare in the general population, stress fractures of the tarsal navicular bone are frequently incurred by professional

This article is part of the Topical Collection on Foot and Ankle Sports Medicine

Rachel J. Shakked

Rachel.shakked@rothmaninstitute.com

1 Rothman Institute, 3300 Tillman Drive, 2nd Floor, Bensalem, PA 19020-2071, USA

2 University of Texas McGovern Medical School, Houston, TX, USA

3 Hospital for Special Surgery, New York, NY, USA athletes. They represent $25 \%$ of all stress fractures and appear to have a predilection for young male athletes. In a study of 200 navicular stress fractures, the majority of fractures were observed in males in their mid-20s, $98.5 \%$ of whom were athletes $[1 \cdot, 2]$. Navicular stress fractures are associated with an extended recovery time; they accounted for only $8 \%$ of total foot injuries in a series of rugby players, but $22 \%$ of the player absence with average return to play of 188 days [3]. According to the literature, an overwhelming amount of these injuries are seen in short-distance runners and basketball players [4-6]. Navicular stress fractures are more likely in these subgroups because these athletes do a lot of jumping, rapid cutting, and explosive movements; they frequently engage in forceful push off, with frequent and repetitive loading of the forefoot $[7,8]$.

\section{Anatomy and biomechanics}

Specific anatomic, vascular, and biomechanical properties predispose the navicular bone to overuse injury. The navicular is a saddle-shaped bone located between the head of the talus and the three cuneiform bones [9]. The navicular serves as an integral structural link between the midfoot and the hindfoot, allowing for force transmission and push off during gait. Moreover, the navicular provides stability to the longitudinal and transverse arches of the foot and is considered the keystone of the medial longitudinal arch [7].

The navicular's blood supply is derived from the dorsalis pedis (dorsal navicular) and posterior tibial (plantar navicular) arteries [10•]. This arterial network enters the navicular throughout its non-articular surfaces and branches out medially and laterally, leaving the central third relatively avascular $[7,11]$. A recent cadaver study identified this avascular region in a subset of specimens and suggested that perhaps patients 
with this anatomic variant are at increased risk for navicular stress fracture [10•]. The tarsal navicular's limited vascularity has important applications: without treatment, patients with navicular stress fractures may have difficulty healing because of the bone's limited vascular supply $[4,12]$. As a result of this decreased blood flow, those with navicular stress fractures tend to experience delayed healing, high rates of nonunion, and prolonged time out of sport [13].

The tarsal navicular's unique anatomic location subjects it to medial and lateral compression forces from the first and second metatarsocuneiform joints, respectively [9]. While the medial forces are shared with the talar head, the lateral forces are borne by the navicular alone. As a result of this unequal distribution of forces, maximum sheer stress is concentrated at the central third of the bone [7, 13]. Moreover, contraction of the tibialis posterior tendon, which inserts on the navicular's medial tuberosity, elevates the medial stress experienced by the navicular [9]. With repeated compression of the navicular, such as during running, the majority of forces are concentrated at the center of the bone, causing the navicular to be repeatedly "bent" at the avascular zone [14-16].

The navicular's limited vascularity coupled with stress overload and heightened activity levels make this bone particularly vulnerable to stress fractures. Moreover, this type of injury is considered to be high-risk, as these same characteristics interfere with proper healing. As such, an aggressive diagnostic approach and surgical intervention are often required.

\section{Pathogenesis and etiology}

Navicular stress fractures are a type of chronic overuse injury most often seen following periods of intense exercise without adequate rest and recovery time. In such instances, the navicular bone is subjected to repetitive and continuous overload, resulting in microfractures and generating a so-called weak spot in the foot architecture. With persistent loading, a true cortical break (i.e., a stress fracture) eventually occurs [4, 13].

\section{Risk factors}

Both intrinsic and extrinsic factors have been implicated in the pathogenesis of tarsal navicular stress fractures. Intrinsic factors include the patient's anatomy and underlying biologic processes. Factors that have been shown to increase navicular stress fracture risk include previous history of stress fracture, insufficient vascular supply, and unfavorable foot/ankle biomechanics [17]. Although females with nutritional or menstrual disorders related to the female triad are at increased risk for developing stress fractures, young male athletes tend to have a higher rate of navicular stress fracture [17]. Specific anatomic variants, such as having a short first metatarsal and a long second metatarsal, metatarsus adductus, limited subtalar motion, medial narrowing of the talonavicular joint, pes cavus, and reduced ankle dorsiflexion have all been associated with an increased risk of navicular stress fracture [16, 18]. One possible explanation for this phenomenon is that if ankle dorsiflexion is limited, the midfoot will naturally compensate with a larger excursion. Consequently, this increased motion may precipitate navicular impingement during dorsiflexion [7]. Cavus foot may be associated with increased risk of navicular fracture due to decreased shock absorption; first ray dorsiflexion osteotomy has been suggested anecdotally to help with fracture healing [19•]. Talar neck osteophytes are often seen concurrently with navicular stress fractures and may be removed at the time of surgery. There is likely some genetic predisposition in certain patients with bilateral fractures occasionally occurring in 3\% [20]. A recent case series was published on a set of monozygotic twin athletes with similar navicular stress fractures [21].

Extrinsic factors that increase the risk of navicular stress fracture include poor nutritional status, excessive training regimen (resulting in overloading and chronic fatigue), and inadequate footwear. It is especially important to evaluate for the female triad: irregular menses, eating disorders, and decreased bone mineral density. Recent research revealed that the presence of female triad-related risk factors increases female patient risk of bony stress injury, especially low bone mineral density and participation of greater than $12 \mathrm{~h}$ of exercise per week [22]. Furthermore, there appears to be an additive effect, with more risk factors associated with greater risk of stress reaction.

\section{Role of vitamin D}

Vitamin D levels have become an important factor in the diagnosis and treatment of stress fractures. Insufficient vitamin $\mathrm{D}$ limits the intestinal absorption of calcium which leads to upregulation of parathyroid hormone (PTH). This causes increased bone resorption which can result in fractures and impaired bone healing [23•]. Vitamin D also functions to upregulate the transcription of genes involved in neovascularization in areas of endochondral ossification such as a healing fracture site [24]. Vitamin D deficiency is typically characterized as serum level of 25-hydroxyvitamin $\mathrm{D}_{3}$ of less than $20 \mathrm{ng} / \mathrm{mL}$ and insufficiency is between 20 and $31 \mathrm{ng} / \mathrm{mL}$ [25]. In a study of 723 surgical foot and ankle patients, more than half had vitamin D insufficiency; men and patients with darker skin were at greater risk for vitamin deficiency [26]. However, there is some data to suggest that Vitamin D levels decrease after a fracture indicating that the hypovitaminosis D is actually a result of the fracture rather than a risk factor [27]. Nonetheless, vitamin D deficiency is frequently seen in patients with lower extremity fractures, and Vitamin D and PTH pathways are therefore logical biological targets to improve healing and prevent fractures $[28 \bullet, 29]$. 


\section{Clinical evaluation}

Patients typically present with complaints of poorly localized, midfoot tenderness or ill-defined soreness/cramping sensation in the foot that is aggravated by weight bearing and initiation of activity. Often, the maximum area of tenderness occurs along a nickel-sized area in the center of the proximal dorsal navicular known as the N-spot [15]. Studies demonstrated that $81 \%$ of patients with navicular stress fractures have tenderness to palpation at the $\mathrm{N}$-spot [2]. This vague pain tends to be insidious in onset, and may radiate to the medial aspect of the longitudinal $\operatorname{arch}[2,9]$. Initially, athletes may only experience this pain at the beginning of activity, and engaging in certain activities (such as cutting, sprinting, pushing off, and jumping) may increase the pain; with time, however, the onset of pain during activity occurs earlier and lasts longer into rest time.

On physical examination, patients often endorse pain and tenderness along the dorsal navicular with palpation, standing on their tiptoes, and while performing a single leg hop $[9,12]$. Ankle dorsiflexion and/or subtalar joint motion may also be limited [2]. Strength testing and the appearance of the foot are typically unremarkable.

Recent research has revealed that definitive diagnosis of navicular stress fracture is, on average, delayed 4 to 7 months from the onset of pain [2,9]. Diagnosis is often made even more challenging because athletes may minimize their symptoms until the pain is unbearable, at which point the stress fracture has likely worsened. Moreover, in an attempt to reduce stresses through the midfoot and compensate for their injury, athletes may alter their gate or foot strike pattern [9].

\section{Classification}

In an attempt to streamline prognosis and management of stress fractures, Boden developed a classification system that subdivided stress fractures into low-risk and high-risk categories [30]. Low-risk fractures have an excellent prognosis with few to no complications and successful return to sport. Diagnosis is usually made through the history and physical exam, sometimes with the addition of radiographs. The majority is successfully managed with conservative treatment, such as rest and activity restriction.

Less commonly, stress fractures may occur at an area that is considered to be high-risk. These locations "have a region of maximal tensile load in a zone of diminished blood flow that is vulnerable to stress injury, with suboptimal healing potential," like the tarsal navicular [13]. This subset has a greater risk of fracture progression, delayed healing, chronic pain, and nonunion - especially when the diagnosis is delayed. While the history and physical exam are important components of the workup, advanced imaging modalities are required for diagnosis, and more aggressive treatment is almost always necessitated.
Although they are relatively rare, they have significant implications, as they can cause significant morbidity in highperformance athletes if not diagnosed and managed properly.

To help focus treatment approach, Saxena et al. developed a tarsal navicular stress fracture classification system based on computed tomography (CT) findings [31].

- Type $I=$ fracture in dorsal cortex

- Type II = fracture extends from dorsal cortex into navicular body

- Type III = complete fracture through both cortices

- Sub-classified by avascular, cystic, and sclerotic changes

The navicular's limited vascularity coupled with stress overload and heightened activity levels make this bone particularly vulnerable to stress fractures. Moreover, this type of injury is considered to be high-risk, as these same characteristics interfere with proper healing. As such, an aggressive diagnostic approach and surgical intervention are often required.

\section{Imaging}

Due to the vague presentation of navicular stress fractures, imaging is a key aspect of the clinical evaluation. As such, making an accurate and timely diagnosis requires a high index of suspicion coupled with appropriate utilization of imaging techniques.

\section{Radiographs}

Routine weight-bearing radiographs (AP, lateral, and oblique) are typically the initial imaging modality of choice. However, these should not be used in isolation, as radiographs have been shown to have very low sensitivity for navicular stress fractures $[9,15]$. Moreover, most navicular fractures do not involve the plantar cortex, making them difficult to identify on radiographs until osteoclastic resorption has occurred [7]. Rather, these images should be used to rule out other potential causes of medial foot and ankle pain, such as malalignment, talar neck spurring, or capsular avulsions.

\section{Triple-phase bone scan}

Given their high sensitivity and high positive predictive value in identifying these fractures, bone scans may be used to screen for navicular stress fractures $[9,32,33]$. Despite the high sensitivity, a positive bone scan is not specific for this navicular stress fracture. Moreover, bone scans lack anatomic resolution and do not provide an accurate depiction of the specific fracture pattern. As such, this imaging modality has largely been replaced by magnetic resonance imaging (MRI). 


\section{MRI}

MRI is considered the gold standard, as it is the best at detecting bone edema and stress reaction which may occur prior to stress fracture. Navicular stress reactions present with similar symptoms as stress fractures, but lack an obvious fracture line on CT. By detecting such stress reactions early, steps may be taken to prevent the stress reaction from progressing into a full-blown stress fracture. MRI has the additional advantage of avoiding radiation exposure.

\section{CT}

CT plays an important role in pre-operative planning, as it provides the best visualization of the fracture line. Using the aforementioned CT-based classification system designed by Saxena et al., navicular stress fractures can be divided into separate groups with associated treatment schemes [31]. CT may also help to identify sclerosis at the fracture edges which may portend a poorer prognosis and potential nonunion. Furthermore, CT can also be used to monitor healing. Dorsal cortical proliferation, which is typically the first radiologic sign of healing, can be seen as early as 6 weeks following the injury using CT [7]. Bony healing and consolidation is seen later, at around 3-4 months post-injury. Of note, repeat $\mathrm{CT}$ and MRI scans are often recommended to ensure positive signs of healing prior to return to sports.

\section{Treatment}

\section{Non-operative management}

High healing rates of non-displaced navicular fractures have been reported with immobilization and protected weight bearing for 6 to 8 weeks [2]. However, the study includes patients diagnosed by bone scan which could simply be stress reactions typically expected to improve with non-operative treatment. Furthermore, the study lacks confirmation of healing on cross-sectional imaging. A more recent study provided more support for the non-operative treatment of navicular stress fractures with 19 of 22 patients going on to return to sport at an average of 5.6 months after injury; CT confirmation of fracture healing in these cases was also not presented [20]. Furthermore, the authors discuss that there remained a fracture line in some cases but that athletes were still able to return to activity without symptoms. The longevity of an athletic career in a patient with an asymptomatic persistent fracture line is yet unknown. Non-operative treatment of a navicular stress may be an option in patients with an incomplete fracture or type 1 in the Saxena classification. Aside from immobilization and restricted weight bearing, there are other non-operative treatments that can be utilized alone or in conjunction with surgical treatment.

\section{Bone stimulator}

When treating non-operatively, utilizing a bone stimulator as an adjunctive modality does not seem to pose any harm, but the benefit has not been proven. Several randomized, controlled trials have demonstrated faster fracture healing of the distal radius and tibial fractures with the use of low-intensity pulsed ultrasound compared to placebo (Heckman et al. JBJS 1994, Kristiansen et al. JBJS 1997). A recent randomized controlled trial failed to show a benefit of capacitively coupled electric fields when used for medial tibial stress fractures, except in the more severe cases [34]. The authors suggest that use of low intensity pulsed ultrasound bone stimulators in elite athletes is reasonable to potentially accelerate the healing time to some degree.

\section{Shock wave therapy}

Shock wave therapy (SWT) is increasingly popular for the treatment of tendonitis and other soft tissue conditions, although it was originally described to treat bony conditions after increased bone formation was seen at the time of lithotripsy procedures [35]. There are multiple studies supporting its use in the treatment of fracture nonunions, but little literature supporting use in stress fractures [36-43]. The procedure is safe and fast and is a useful adjunct when treating navicular stress fractures operatively and non-operatively. Prospective, randomized studies are needed to better delineate the advantages of using SWT.

\section{Vitamin D supplementation}

Vitamin D supplementation has significant support in the literature in the setting of stress fractures. In an osteoporotic rat model, vitamin D3 supplementation resulted in biomechanically improved callus formation at the fracture site as compared to rats without supplementation [44]. A prospective, randomized, placebo-controlled trial found a $20 \%$ reduction in stress fracture incidence when female Navy recruits were given $2000 \mathrm{mg}$ calcium and 800 IU vitamin D supplementation over a period of 8 weeks [45]. The general consensus is that Vitamin D and calcium supplementation aid in fracture healing, although the exact reasons are not elucidated in the literature as of yet $\left[23^{\bullet}\right]$.

\section{Teriparatide}

Teriparatide is a recombinant human PTH that stimulates osteoblasts to generate new bone when given intermittently [46]. Use in treatment for osteoporosis has been successful, and there is now some literature to support its off-label use in treating fractures and nonunions [47]. A randomized, controlled trial in rats of intermittent recombinant PTH administration demonstrated improved quality and strength of the fracture callus that was 

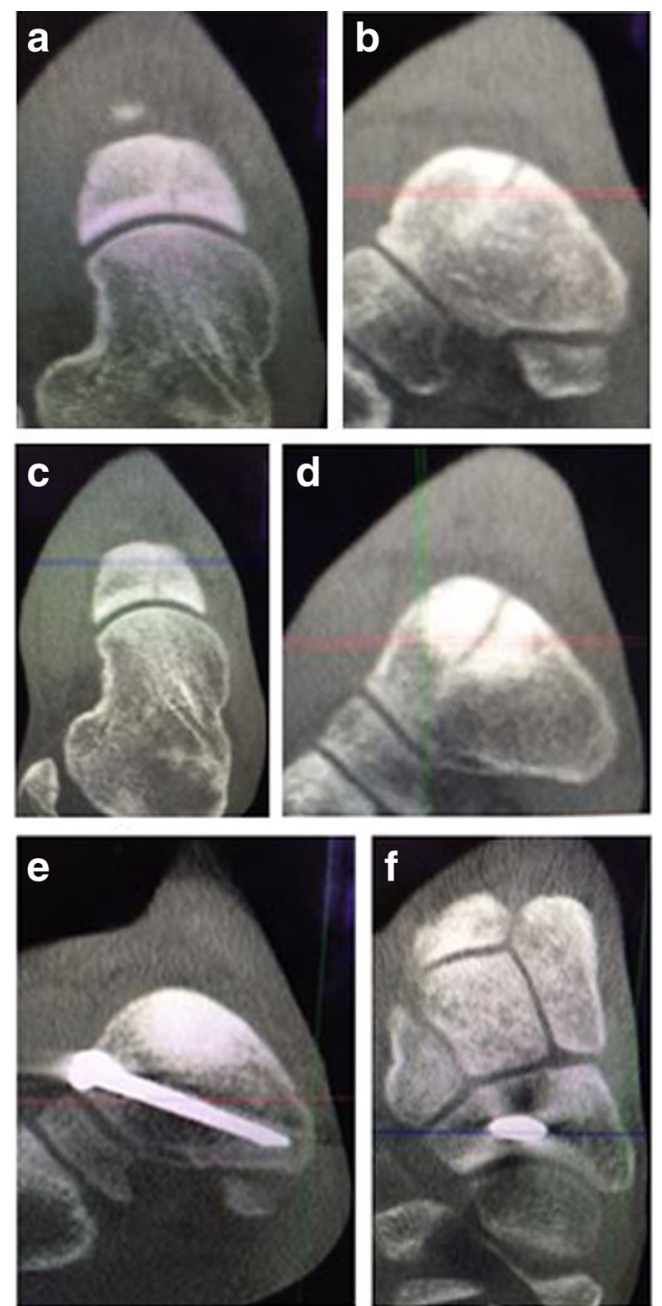

Fig. 1 Coronal (a) and sagittal (b) weight-bearing CT images demonstrate a type I navicular stress fracture in a division I track athlete. After 6 weeks of non-weight bearing and boot immobilization, the coronal (c) and sagittal (d) weight-bearing CT images demonstrate increased sclerosis and persistence of the fracture line. The patient underwent percutaneous screw fixation with BMAC and CT images (e, f) demonstrate fracture healing at 10 weeks post-operatively

sustained even after the medication was discontinued [46]. In a small randomized, placebo-controlled trial, premenopausal women with acute lower extremity stress fractures treated with recombinant parathyroid hormone had increased bone formation markers and better healing on MRI [48 $]$. The medication was administered via daily injections of $20 \mu \mathrm{g}$. Acceleration of healing with PTH treatment was not supported by this study, although the trend was identified in a large randomized controlled trial evaluating the healing of women with distal radius fractures [47]. In rat studies exposed to high doses of this medication, osteosarcoma was frequently seen as an adverse effect [49]. However, as of 2012, no patient with osteosarcoma had been exposed to teriparatide treatment [50]. Teriparatide administration may be a safe adjunct to both operative and non-operative treatment to encourage healing of navicular stress fractures in select difficult cases.

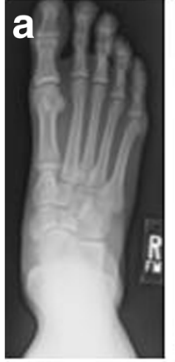

b
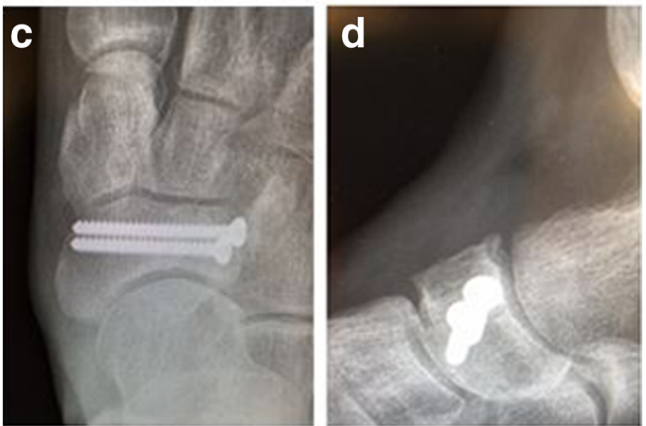

Fig. 2 AP (a) and lateral (b) radiographs show a complete navicular stress fracture in a 20-year-old Olympic triathlete. Fracture healing is seen on AP (c) and lateral (d) radiographs taken at 6 months postoperatively and the patient was permitted to return to training

\section{Operative management}

Surgical treatment of navicular stress fractures is generally preferred in elite athletes and patients with high functional demands. Fitch and colleagues described an "uncertainty" of non-operative management as they observed that navicular stress fractures were slow to heal and frequently went on to nonunion [8]. They also observed that athletes with partial fractures seen on CT would typically experience significant improvement with rest, only to become symptomatic again upon return to play. Of 37 navicular stress fractures, 19 (51\%) failed non-operative treatment and underwent bone grafting with good results; average return to sport was 8 months [8]. In a more recent study, Mallee et al. demonstrated an earlier return to sport at 16.4 weeks in patients treated operatively compared to 21.7 weeks when treated nonoperatively in a cast for 6 weeks [1•]. Khan et al. described a return to sport at 3.8 months after surgery as compared to 5.6 months when treated non-operatively [20].

\section{Bone marrow aspirate concentrate}

Bone marrow aspirate concentrate (BMAC) is also described as an adjunct in the operating room and can be infused at the fracture site to augment healing. A recent technique was published describing injection of BMAC through a partially inserted cannulated screw filled with bone wax in order to infuse the fracture site with progenitor cells and growth factors [51]. The use of BMAC has been shown to improve osteogenesis in vitro and in vivo, although techniques are highly 
Fig. 3 a Dorsal approach to the navicular demonstrating fracture site. b Dental tool is used to debride the fracture site
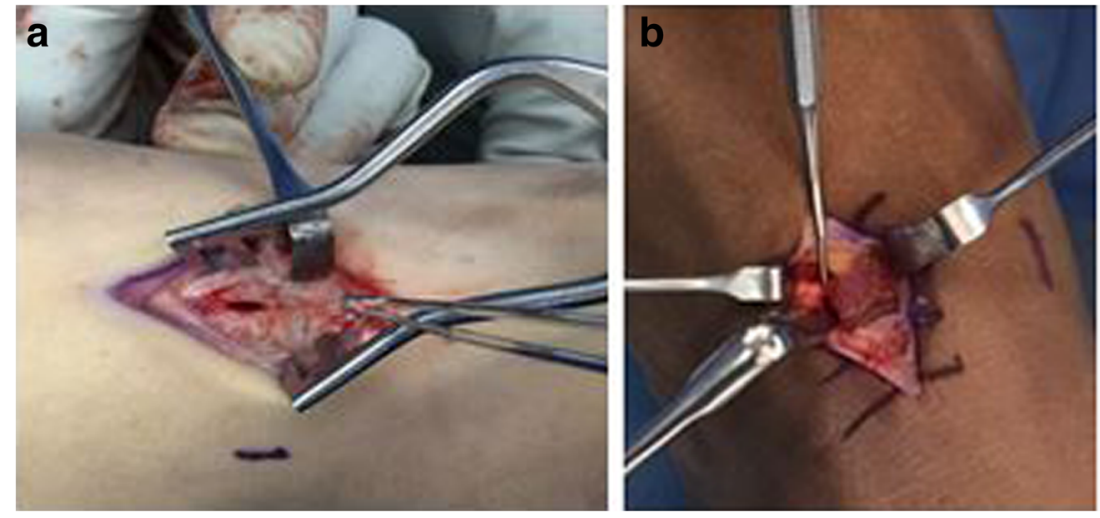

variable and concentration of progenitor cells is inconsistent among studies [52]. Further study on the use of BMAC in the setting of navicular stress fracture is indicated.

\section{Author's preferred treatment algorithm}

Type I fractures can be treated non-operatively with 6 weeks of strict non-weight bearing or with a single percutaneous $3.5-\mathrm{mm}$ screw and earlier gradual weight bearing (see Fig. 1). Type II and III fractures are treated with ORIF using 1- to $23.5-\mathrm{mm}$ screws (see Fig. 2), iliac crest BMAC, and autologous bone dowels obtained from the ipsilateral iliac crest. Anterior ankle impingement should be addressed at the time of surgery as this can limit ankle motion and increase stress in the area of the navicular fracture. Distal tibial cheilectomy can be done through a small open approach or arthroscopic depending on surgeon preference. Athletes may return to full activities when fracture healing is visualized on CT done at 10 weeks at the earliest.

Post-operatively, patients are strictly non-weight bearing for 6 weeks but may mobilize the ankle and the calf. If possible, bone stimulator and shockwave therapy is utilized and vitamin $\mathrm{D}$ supplementation is given to ensure a level over 40 . CT scan is performed at 10 weeks with a goal of $100 \%$ union prior to release to high level athletics to diminish the risk of recurrent fracture. Incomplete healing is suboptimal but would be acceptable in a lower demand patient if asymptomatic.
Author's recommended surgical technique

Operative technique includes a dorsal approach to the navicular taking care to protect the superficial peroneal nerve and the deep neurovascular bundle (see Fig. 3a). The fracture site is identified using an 18-gauge needle and then the fibrous material at the fracture site is debrided using a scalpel and dental pick (see Fig. 3b). The sclerotic fracture edges can be drilled with a 0.045 K-wire to expose healthy bone. After successful debridement, there is typically a gap of several millimeters so autograft with or without BMAC can be added to augment healing. The trocar used to obtain bone marrow aspirate can be used to harvest dowels of cancellous bone from the iliac crest percutaneously (see Fig. 4). A single, 3.5-mm fully-threaded cortical lag screw by technique can be placed percutaneously from medial to lateral. Initially a guide wire is placed and the position is checked on fluoroscopy. Given that the fracture line is often subtle and difficult or impossible to see using standard fluoroscopy, intraoperative CT scan can be performed to confirm good position of the guide wire relative to the fracture line and within the anatomy of the navicular bone (see Fig. 5) [53]. In cases of a complete fracture that is rotationally unstable, an additional 3.5-mm cortical screw can be placed.

\section{Post-operative rehabilitation}

The patient is immobilized in a post-operative splint for 2 weeks and then transitioned to a boot for early range of motion. The patient is non-weight bearing for a period of
Fig. 4 Bone dowels harvested percutaneously from iliac crest (a) with the trocar used for the aspiration (b)
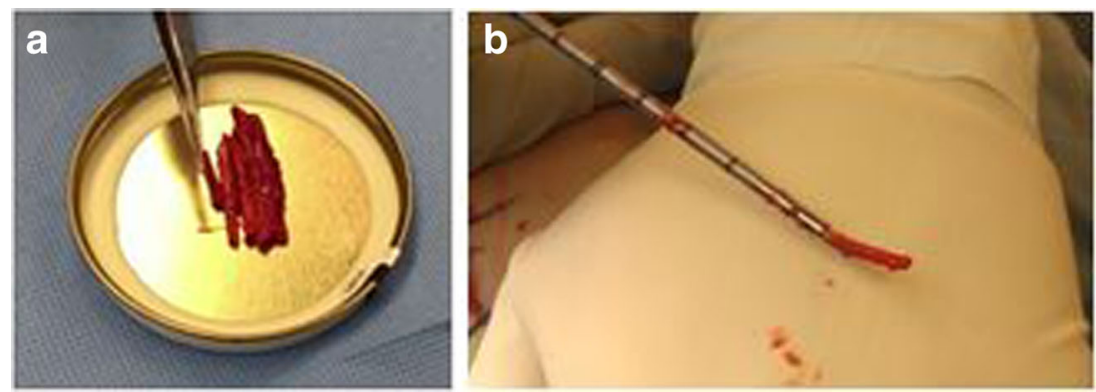


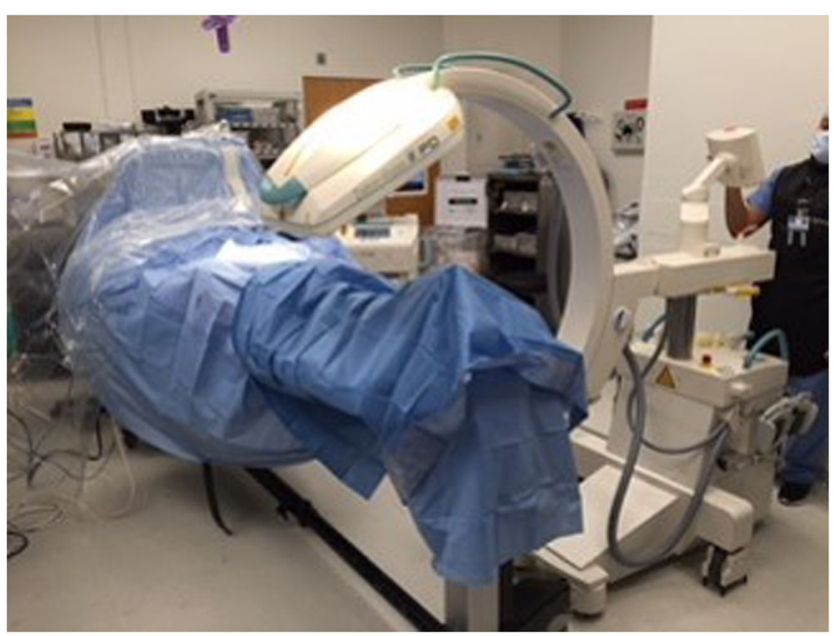

Fig. 5 O-arm used to obtain intraoperative CT scan

6 weeks and then permitted to initiate gradual weight bearing as tolerated in the boot for the next 6 weeks. Functional rehabilitation is initiated with walker boot for weight bearing activity and the initiation of low-impact rehab such as cycling. Return to play is generally delayed until at least 6 months, but varies depending on recovery progress, overall clinical picture, and the demands of certain sports. Weight-bearing CT can be performed at 10 to 12 weeks to assess for definitive fracture healing and activities are progressed accordingly.

\section{Outcomes}

Patient outcome is variable although it does correlate with fracture severity [31]. Nonunion after operatively treated navicular stress fractures may be as high as $20 \%$ based on post-operative CT imaging [19•]. AOFAS and SF-36 scores are approximately 92 in cases that heal after surgery, but are in the low 70 s in cases that go on to nonunion [19•]. McCormick et al. observed that the cases that went on to nonunion were complete and displaced fractures, whereas $100 \%$ of the partial navicular stress fractures went on to heal uneventfully. Sclerosis of the fracture edges is also thought to be a factor that suggests navicular nonunion. Of the complete, displaced fractures, only $50 \%$ went on to union; those that healed included the use of autologous bone grafting at the fracture site. This was not statistically significant but may be considered a trend supporting the use of autograft in these difficult fractures.

\section{Return to sport}

The stress fracture takes about 4 months to unite and return to sports is usually feasible around 5 months post-operatively [7]. Other studies have shown a return to sports at about 4 months post-operatively $[1 \bullet, 54]$. Given the poor vascularity and elevated risk of nonunion of these fractures, it is preferred to confirm fracture healing on cross-sectional imaging such as MRI or CT prior to allowing the patient to return to sports.

\section{Prevention}

Identifying those patients at the highest risk for stress fracture can help to focus treatment. As reviewed above, anatomic and biologic risk factors can both increase a patient's risk for stress fracture. There is some evidence to suggest genetic predisposition based on a work in 210 Israel Defense Force soldiers and 518 elite athletes evaluating genetic variability in the P2X7 receptor on osteoblasts and osteoclasts [55]. In the future, targeting these patients with treatment like Vitamin D supplementation could potentially reduce the incidence of stress fracture [45].

\section{Conclusion}

Navicular stress fractures are prevalent in athletes and tend to have poor healing potential related to the unique anatomy and vascular supply. Although some cases can be treated non-operatively, there is a trend towards operative management to allow definitive healing shown on cross-sectional imaging and earlier return to play with low risk of reinjury. More research is necessary in the future to evaluate the use of adjunctive treatment such as BMAC, teriparatide, and Vitamin D supplementation.

\section{Compliance with ethical standards}

Conflict of interest None of the authors has a financial or proprietary interest in the subject matter or materials discussed in the manuscript, including, but not limited to, employment, consultancies, stock ownership, honoraria, and paid expert testimony.

Human and animal rights and informed consent This article does not contain any studies with human or animal subjects performed by any of the authors.

\section{References}

Papers of particular interest, published recently, have been highlighted as:

\section{- Of importance}

1. Mallee WH, Weel H, van Dijk CN, van Tulder MW, Kerkhoffs $\mathrm{GM}$, Lin CW, et al. Surgical versus conservative treatment for high-risk stress fractures of the lower leg (anterior tibial cortex, navicular and fifth metatarsal base): a systematic review. Br J Sports Med. 2015;49:370-6. Systematic review of lower extremity stress fractures showing earlier return to sports after 
operatively treated navicular stress fractures compared to non-surgical treatment.

2. Torg JS, Pavlov H, Cooley LH, Bryant MH, Arnoczky SP, Bergfeld J, et al. Stress fractures of the tarsal navicular. A retrospective review of twenty-one cases. J Bone Joint Surg Am. 1982;64(5):700-12.

3. Pearce CJ, Brooks JH, Kemp SP, Calder JD. The epidemiology of foot injuries in professional rugby union players. Foot Ankle Surg : Off J Eur Soc Foot Ankle Surg. 2011;17(3):113-8.

4. Weel H, Opdam KTM, Kerkhoffs GM. Stress fractures of the foot and ankle in athletes, an overview. Clin Res Foot Ankle. 2014;2(4):160.

5. Mann JA, Pedowitz DI. Evaluation and treatment of navicular stress fractures, including nonunions, revision surgery, and persistent pain after treatment. Foot Ankle Clin. 2009;14(2):187-204.

6. Snyder RA, Koester MC, Dunn WR. Epidemiology of stress fractures. Clin Sports Med. 2006;25(1):37-52. viii.

7. Hossain M, Clutton J, Ridgewell M, Lyons K, Perera A. Stress fractures of the foot. Clin Sports Med. 2015;34(4):769-90.

8. Fitch KD, Blackwell JB, Gilmour WN. Operation for non-union of stress fracture of the tarsal navicular. J Bone Joint Surg Br Vol. 1989;71(1):105-10.

9. Gross CE, Nunley 2nd JA. Navicular stress fractures. Foot Ankle Int. 2015;36(9):1117-22.

10. McKeon KE, McCormick JJ, Johnson JE, Klein SE. Intraosseous and extraosseous arterial anatomy of the adult navicular. Foot Ankle Int. 2012;33(10):857-61. Cadaver study mapping the arterial supply to the navicular.

11. Waugh W. Structural deformities of the outer third of the adult tarsal navicular. Proc Royal Soc Med. 1956;49(11):965-7.

12. Kahanov L, Eberman LE, Games KE, Wasik M. Diagnosis, treatment, and rehabilitation of stress fractures in the lower extremity in runners. Open Access J Sports Med. 2015;6:87-95.

13. McInnis KC, Ramey LN. High-risk stress fractures: diagnosis and management. PM \& R : J Injury, Function, Rehab. 2016;8(3 Suppl): S113-24.

14. Mann G, Hetsroni I, Constantini N, Dolev E, Palmanovich E, Finsterbush A, et al. Navicular stress fractures of the foot. Sports Injuries. 2015;168:2103-13.

15. Khan KM, Brukner PD, Kearney C, Fuller PJ, Bradshaw CJ, Kiss ZS. Tarsal navicular stress fracture in athletes. Sports Med. 1994;17(1):65-76.

16. Bennell K, Matheson G, Meeuwisse W, Brukner P. Risk factors for stress fractures. Sports Med. 1999;28(2):91-122.

17. Wright AA, Taylor JB, Ford KR, Siska L, Smoliga JM. Risk factors associated with lower extremity stress fractures in runners: a systematic review with meta-analysis. Br J Sports Med. 2015;49(23): 1517-23.

18. Ingalls J, Wissman R. The os supranaviculare and navicular stress fractures. Skelet Radiol. 2011;40(7):937-41.

19. McCormick JJ, Bray CC, Davis WH, Cohen BE, Jones 3rd CP, Anderson RB. Clinical and computed tomography evaluation of surgical outcomes in tarsal navicular stress fractures. Am J Sports Med. 2011;39(8):1741-8. Case series of 10 operatively treated navicular stress fractures with functional and radiologic outcomes at 42 months.

20. Khan KM, Fuller PJ, Brukner PD, Kearney C, Burry HC. Outcome of conservative and surgical management of navicular stress fracture in athletes. Eighty-six cases proven with computerized tomography. Am J Sports Med. 1992;20(6):657-66.

21. Van Meensel AS, Peers K. Navicular stress fracture in highperforming twin brothers: a case report. Acta Orthop Belg. 2010;76(3):407-12.

22. Barrack MT, Gibbs JC, De Souza MJ, Williams NI, Nichols JF, Rauh MJ, et al. Higher incidence of bone stress injuries with increasing female athlete triad-related risk factors: a prospective multisite study of exercising girls and women. Am J Sports Med. 2014;42(4):949-58.
23. Gorter EA, Hamdy NA, Appelman-Dijkstra NM, Schipper IB. The role of vitamin D in human fracture healing: a systematic review of the literature. Bone. 2014;64:288-97. Systematic review of in vitro and in vivo studies on Vitamin $D$ and its effect on fracture healing.

24. Michelson JD, Charlson MD. Vitamin D status in an elective orthopedic surgical population. Foot Ankle Int. 2016;37(2):186-91.

25. Angeline ME, Gee AO, Shindle M, Warren RF, Rodeo SA. The effects of vitamin D deficiency in athletes. Am J Sports Med. 2013;41(2):461-4.

26. Bogunovic L, Kim AD, Beamer BS, Nguyen J, Lane JM. Hypovitaminosis D in patients scheduled to undergo orthopaedic surgery: a single-center analysis. J Bone Joint Surg Am. 2010;92(13):2300-4.

27. Sprague S, Petrisor B, Scott T, Devji T, Phillips M, Spurr H, et al. What is the role of vitamin D supplementation in acute fracture patients? A systematic review and meta-analysis of the prevalence of hypovitaminosis D and supplementation efficacy. J Orthop Trauma. 2016;30(2):53-63.

28. Smith JT, Halim K, Palms DA, Okike K, Bluman EM, Chiodo CP. Prevalence of vitamin D deficiency in patients with foot and ankle injuries. Foot Ankle Int. 2014;35(1):8-13. Prospective case control study showing greater risk of Vitamin D insufficiency in patients with low energy lower extremity fractures.

29. Shimasaki Y, Nagao M, Miyamori T, Aoba Y, Fukushi N, Saita Y, et al. Evaluating the risk of a fifth metatarsal stress fracture by measuring the serum 25-hydroxyvitamin D levels. Foot Ankle Int. 2016;37(3):307-11.

30. Boden BP, Osbahr DC. High-risk stress fractures: evaluation and treatment. J Am Acad Orthop Surg. 2000;8(6):344-53.

31. Saxena A, Fullem B, Hannaford D. Results of treatment of 22 navicular stress fractures and a new proposed radiographic classification system. J Foot Ankle Surg : Off Publ Am College Foot Ankle Surg. 2000;39(2):96-103.

32. Burne SG, Mahoney CM, Forster BB, Koehle MS, Taunton JE, Khan KM. Tarsal navicular stress injury: long-term outcome and clinicoradiological correlation using both computed tomography and magnetic resonance imaging. Am J Sports Med. 2005;33(12):1875-81.

33. Pavlov H, Torg JS, Freiberger RH. Tarsal navicular stress fractures: radiographic evaluation. Radiology. 1983;148(3):641-5.

34. Beck BR, Matheson GO, Bergman G, Norling T, Fredericson M, Hoffman AR, et al. Do capacitively coupled electric fields accelerate tibial stress fracture healing? A randomized controlled trial. Am J Sports Med. 2008;36(3):545-53.

35. Graff J, Richter KD, Pastor J. Effect of high-energy shock waves on bony tissue. Urolithiasis. 1989:997-8.

36. Valchanou VD, Michailov P. High energy shock waves in the treatment of delayed and nonunion of fractures. Int Orthop. 1991;15(3): $181-4$.

37. Schaden W, Fischer A, Sailler A. Extracorporeal shock wave therapy of nonunion or delayed osseous union. Clin Orthop Relat Res. 2001;387:90-4.

38. Cacchio A, Giordano L, Colafarina O, Rompe JD, Tavernese E, Ioppolo F, et al. Extracorporeal shock-wave therapy compared with surgery for hypertrophic long-bone nonunions. J Bone Joint Surg Am. 2009;91(11):2589-97.

39. Rompe JD, Rosendahl T, Schollner C, Theis C. High-energy extracorporeal shock wave treatment of nonunions. Clin Orthop Relat Res. 2001;387:102-11.

40. Xu ZH, Jiang Q, Chen DY, Xiong J, Shi DQ, Yuan T, et al. Extracorporeal shock wave treatment in nonunions of long bone fractures. Int Orthop. 2009;33(3):789-93.

41. Taki M, Iwata O, Shiono M, Kimura M, Takagishi K. Extracorporeal shock wave therapy for resistant stress fracture in athletes: a report of 5 cases. Am J Sports Med. 2007;35(7):1188-92. 
42. Wang CJ, Huang HY, Chen HH, Pai CH, Yang KD. Effect of shock wave therapy on acute fractures of the tibia: a study in a dog model. Clin Orthop Relat Res. 2001;387:112-8.

43. Moretti B, Notarnicola A, Garofalo R, Moretti L, Patella S, Marlinghaus E, et al. Shock waves in the treatment of stress fractures. Ultrasound Med Biol. 2009;35(6):1042-9.

44. Fu L, Tang T, Miao Y, Hao Y, Dai K. Effect of 1,25-dihydroxy vitamin D3 on fracture healing and bone remodeling in ovariectomized rat femora. Bone. 2009;44(5):893-8.

45. Lappe J, Cullen D, Haynatzki G, Recker R, Ahlf R, Thompson K. Calcium and vitamin $d$ supplementation decreases incidence of stress fractures in female navy recruits. J Bone Mineral Res : Off J Am Soc Bone Mineral Res. 2008;23(5):741-9.

46. Alkhiary YM, Gerstenfeld LC, Krall E, Westmore M, Sato M, Mitlak BH, et al. Enhancement of experimental fracture-healing by systemic administration of recombinant human parathyroid hormone (PTH 1-34). J Bone Joint Surg Am. 2005;87(4):731-41.

47. Aspenberg P, Genant HK, Johansson T, Nino AJ, See K, Krohn K, et al. Teriparatide for acceleration of fracture repair in humans: a prospective, randomized, double-blind study of 102 postmenopausal women with distal radial fractures. J Bone Mineral Res : Off J Am Soc Bone Mineral Res. 2010;25(2):404-14.

48. Almirol EA, LGao LY, Khurana B, Hurwitz S, Bluman EM, Chiodo CP, et al. Short-term effects of teriparatide versus placebo on bone biomarkers, structure, and fracture healign in women with lower-extremity stress fractures: a pilot study. J Clin Transl Endocrinol. 2016;5:7-14. Randomized controlled trial showing benefit of teriparatide administration for lower extremity stress fractures.

49. Tashjian Jr AH, Gagel RF. Teriparatide [human PTH(1-34)]: 2.5 years of experience on the use and safety of the drug for the treatment of osteoporosis. J Bone Mineral Res : Off J Am Soc Bone Mineral Res. 2006;21(3):354-65.

50. Andrews EB, Gilsenan AW, Midkiff K, Sherrill B, Wu Y, Mann $\mathrm{BH}$, et al. The US postmarketing surveillance study of adult osteosarcoma and teriparatide: study design and findings from the first 7 years. J Bone Mineral Res : Off J Am Soc Bone Mineral Res. 2012;27(12):2429-37.

51. Adams SB, Lewis Jr JS, Gupta AK, Parekh SG, Miller SD, Schon LC. Cannulated screw delivery of bone marrow aspirate concentrate to a stress fracture nonunion: technique tip. Foot Ankle Int. 2013;34(5):740-4.

52. Gianakos A, Ni A, Zambrana L, Kennedy JG, Lane JM. Bone marrow aspirate concentrate in animal long bone healing: an analysis of basic science evidence. J Orthop Trauma. 2016;30(1):1-9.

53. Hsu AR, Lee S. Evaluation of tarsal navicular stress fracture fixation using intraoperative O-arm computed tomography. Foot Ankle Specialist. 2014;7(6):515-21.

54. Saxena A, Fullem B. Navicular stress fractures: a prospective study on athletes. Foot Ankle Int. 2006;27(11):917-21.

55. Varley I, Greeves JP, Sale C, Friedman E, Moran DS, Yanovich R, et al. Functional polymorphisms in the $\mathrm{P} 2 \mathrm{X} 7$ receptor gene are associated with stress fracture injury. Purinergic Signal. 2016;12(1):103-13. 